\title{
BIBLIOMETRIA, HISTÓRIA E GEOGRAFIA DA PESQUISA BRASILEIRA EM EROSÃO ACELERADA DO SOLO ${ }^{(1)}$
}

\author{
Alberto Giaroli de Oliveira Pereira Barretto( ${ }^{(2)}$, Marcelo Geraldo \\ Estriga Barros ${ }^{(3)} \&$ Gerd Sparovek $^{(4)}$
}

\begin{abstract}
RESUMO
Há poucos estudos sobre a história da ciência do solo e, no Brasil, essa matéria ainda não recebeu maior atenção por parte de sua comunidade científica. Este trabalho focaliza a formação histórica da pesquisa brasileira em erosão acelerada do solo a partir de uma análise bibliométrica e geográfica, com base numa ampla compilação de artigos científicos publicados sobre o tema por autores vinculados a instituições brasileiras. A metodologia envolveu o armazenamento, em um banco de dados dimensional, estruturado especificamente para esse objetivo, de informações espaciais e bibliométricas. Indicadores quantitativos foram calculados, e a geografia da pesquisa foi mapeada por meio de consultas SQL e ferramentas de geoprocessamento. Os resultados apontaram para gênese recente da pesquisa brasileira em erosão acelerada do solo e centralização da produção científica e formação de linhas em instituições e autores do Sul e Sudeste do Brasil. Ainda, a análise dos dados temáticos indicou predominância do enfoque da erosão a partir de uma perspectiva agrícola e grande ênfase na pesquisa dos fatores do modelo USLE de estimativa de erosão.
\end{abstract}

Termos de indexação: geoprocessamento, erosão hídrica, banco de dados.

\footnotetext{
(1) Parte da Dissertação de Mestrado apresentada pelo primeiro autor ao Programa de Pós-Graduação em Solos e Nutrição de Plantas da Escola Superior de Agricultura "Luiz de Queiroz", Universidade de São Paulo - USP/ESALQ. Recebido para publicação em junho de 2007 e aprovado em setembro de 2008.

(2) Programa de Pós-Graduação em Solos e Nutrição de Plantas, Escola Superior de Agricultura "Luiz de Queiroz" - ESALQ. Caixa Postal 09, Av. Pádua Dias 11, CEP 13418-900 Piracicaba (SP). E-mail: abarrett@esalq.usp.br

${ }^{(3)}$ Instituto de Matemática e Estatística (USP/IME). E-mail: mestriga@gmail.com

(4) Professor do Departamento de Solos e Nutrição de Plantas, USP/ESALQ. E-mail: gerd@esalq.usp.br
} 


\title{
SUMMARY: BIBLIOMETRICS, HISTORY AND GEOGRAPHY OF BRAZILIAN RESEARCHON ACCELERATED SOIL EROSION
}

\begin{abstract}
Soil science history studies are rare and the Brazilian scientific community has not given substantial attention to this subject yet. The present study focused on the formation of research on accelerated soil erosion in the Brazil from a bibliometric perspective. A comprehensive database of published scientific papers was organized in a relational database and analyzed by SQL queries and GIS tools. These data were used to calculate quantitative indicators and spatial distribution patterns. Results indicate a recent development of research on accelerated soil erosion in Brazil by few institutions and authors in the South and Southeast regions. Moreover, a thematic analysis indicated the agricultural perspective as the main focus of erosion studies, with a great emphasis on the USLE prediction model.
\end{abstract}

Index terms: GIS; water erosion; database.

\section{INTRODUÇÃO}

A ciência do solo é relativamente jovem. Ela se originou da apropriação de ferramentas e técnicas de ciências básicas, como a química, biologia, física, matemática, aplicando-as em problemas de cunho agrícola ou ambiental. Nesse processo, ela foi levada por direito à condição de ciência autônoma com o desenvolvimento de suas próprias técnicas e ferramentas e se fragmentou em várias subdisciplinas, das quais a história (da ciência do solo) foi sistematicamente negligenciada (van Baren et al., 2000), resultando em poucos, senão raros, trabalhos relacionados ao tema. Por outro lado, dados da $\mathrm{CAB}$ Abstracts $^{\circledR}$ e Web of Science ${ }^{\circledR}$ (ISI), analisados por Hartemink (1999), mostram que, desde a década de 1960 até o final de 1990, o número de publicações relacionadas à área de ciência do solo aumentou continuamente (5 \% ao ano), atingindo em 1999 aproximadamente 10.000 publicações por ano, das quais $70 \%$ escritas em inglês e $99 \%$ no formato de artigo científico. Nesse contexto, pesquisas históricas passam pela necessidade de análise de grande quantidade de material bibliográfico, reforçando o potencial de emprego de ferramentas bibliométricas ${ }^{(5)}$. Estudos bibliométricos, assim como históricos, são raros em ciência do solo. Exemplos deste tipo de abordagem podem ser consultados em: McDonald (1994), que investigou o desenvolvimento e as tendências da ciência do solo, empregando técnicas bibliométricas; Greenland (1997), que fez uma revisão histórica do que havia sido publicado nas 11 edições de "Soil Conditions and Plant Growth" entre $1912 \mathrm{e}$ 1988; e Hartemink (2001), que analisou os 100 volumes da revista Geoderma publicados entre 1967 e 2001. Este trabalho se insere nesse contexto como

\footnotetext{
(5) A bibliometria é definida como a análise estatística de material bibliográfico. A bibliometria surgiu com a intenção de desenvolver ferramentas que elucidassem questões gerais de determinado ramo da ciência operando sobre grandes bases de dados bibliográficas (ISI, PASCAL, BIOSIS, CAB Abstracts, etc.).
}

uma revisão bibliográfica que focaliza a pesquisa brasileira em erosão acelerada do solo desde sua formação, empregando ferramentas de bibliometria e tecnologia de informação (geoprocessamento, bancos de dados, Sistema de Informação Geográfica - SIG), ampliando o alcance de uma revisão bibliográfica tradicional.

Os objetivos deste trabalho foram: reconstituir a linha histórica da pesquisa brasileira em erosão acelerada do solo publicada na forma de artigos científicos; identificar os principais atores institucionais e individuais, e descrever o papel de cada um; desenhar a geografia da formação e atuação desse ramo da ciência do solo.

\section{MATERIAL E MÉTODOS}

A pesquisa brasileira em erosão acelerada do solo foi investigada a partir dos artigos publicados em periódicos nacionais ou internacionais até abril de 2007, por autores vinculados a instituições de pesquisa brasileiras. O período selecionado foi de julho de 1949 a abril de 2007, englobando, portanto, quase 60 anos de pesquisa desde o primeiro artigo publicado no Brasil sobre o tema, em 1949, pela revista Bragantia, do Instituto Agronômico de Campinas.

Foram selecionados 225 artigos, oriundos de cinco periódicos nacionais e 21 estrangeiros, segundo os seguintes critérios: (a) o tema erosão acelerada do solo ser central e não acessório na definição dos objetivos do trabalho publicado; (b) algum dos autores do artigo indicar na publicação vínculo com instituições de ensino ou pesquisa brasileiras; (c) o periódico ser indexado na base de dados Web of Science $^{\circledR}\left(\right.$ ISI ${ }^{(6)}$

\footnotetext{
(6) Os periódicos constantes na base ISI foram retroativamente analisados, isto é, os artigos foram considerados mesmo que a data de publicação fosse anterior à data de inserção do periódico na base ISI.
} 
O critério de seleção de artigos partindo da referência externa à Base ISI não compunha o plano original da pesquisa e surgiu da constatação de que aproximadamente $90 \%$ dos artigos pré-selecionados atendiam a esse critério, de modo que não houve perda significativa de informação com essa restrição, a qual proporcionou ao conjunto analisado maior homogeneidade editorial e ao critério de seleção limites mais objetivamente definidos. A única exceção ao último critério foi a revista Bragantia, editada pelo Instituto Agronômico de Campinas. Esse periódico foi incluído mesmo não sendo indexado pela Base ISI, em razão do seu significativo valor histórico, já que essa é a única fonte de artigos relacionados à pesquisa brasileira em erosão acelerada do solo antes de 1977.

Evidentemente, cometeram-se omissões pontuais, assumidas como erros intrínsecos ao método. Além disso, este não é um estudo histórico genérico sobre a pesquisa em erosão; há neste trabalho um viés temático que focaliza a erosão acelerada do solo e seu controle, o que inibiu a inclusão de artigos científicos em que a erosão é abordada sob outras perspectivas.

Todos os artigos selecionados foram digitalizados ${ }^{(7)}$ e cadastrados em banco de dados dimensional, que permite consultas analíticas complexas, estruturado especificamente para os objetivos deste trabalho. O intuito foi armazenar as informações contidas nos artigos necessárias para caracterizá-los como elementos bibliográficos (autoria, ano de publicação, periódico, etc.) e para descrevê-los tematicamente, segundo uma estrutura de tópicos organizados de forma hierárquica (objetivos tratados, métodos empregados, etc.). Para o cadastramento foi utilizada uma interface construída no "Microsoft Access 2003 e nas análises foi utilizado o sistema OLAP (Online Analytical Processing) do Microsoft ${ }^{\circledR}$ SQLServer 2005.

\section{RESULTADOS E DISCUSSÃO}

A pesquisa brasileira em erosão acelerada do solo é recente. Embora os primeiros trabalhos tenham surgido ainda no final da década de 1940, aproximadamente metade da produção científica, na forma de artigos, foi publicada a partir de 1990 (Figura 1). A conseqüência imediata dessa distribuição é a falta de lastro que justifique a historiografia. A discussão dos dados foi feita num único bloco, não se atendo a uma descrição cronológica subdividida em períodos. Optou-se, em contraposição, por assumir alguns recortes regionais e enfatizar as particularidades das linhas de pesquisa conduzidas em cada instituição.

Embora o periódico Pesq. Agropec. Bras. (PAB) já existisse desde 1966, portanto antes da edição do primeiro número da Revista Brasileira de Ciência do Solo (RBCS) em 1977, o único meio de comunicação científica de trabalhos em erosão acelerada anterior a 1977 foi a revista Bragantia, editada pelo Instituto Agronômico (IAC), da Secretaria de Agricultura e Abastecimento do Estado de São Paulo. O objetivo principal da Bragantia na época era compartilhar o trabalho realizado em suas estações experimentais, localizadas em Campinas, Ribeirão Preto, Mococa e Pindorama. O primeiro conjunto de artigos brasileiros em erosão do solo foi, portanto, formado por 12 trabalhos publicados entre 1949 e 1972 por essa revista $^{(8)}$. A maioria dos trabalhos foi conduzida em talhões experimentais de 100 a $1.000 \mathrm{~m}^{2}$, em que se procurava variar os fatores condicionantes do processo erosivo, como: solo, cobertura vegetal, sistemas de preparo, comprimento de rampa e práticas conservacionistas. Com esse tipo de resultado experimental, ampla gama de assuntos relacionados ao tema pôde ser abordada, como perda de nutrientes, relação erosão-produtividade e relação chuva-erosão;

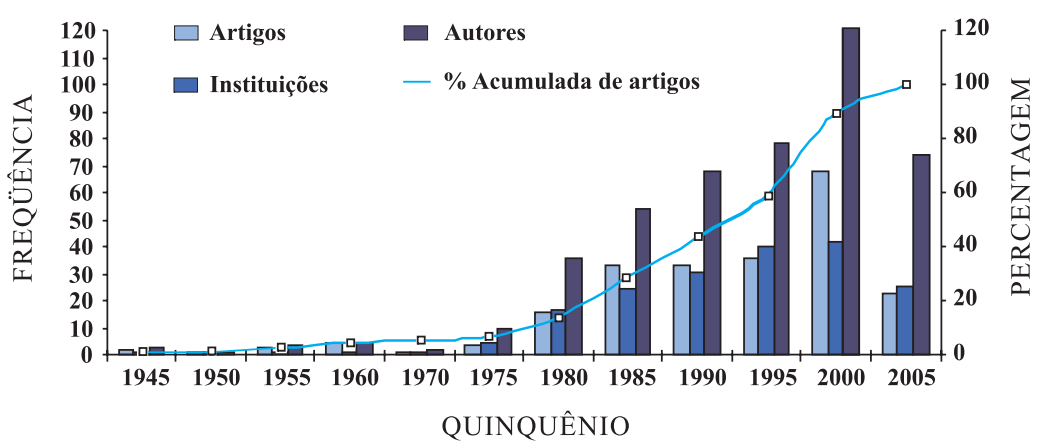

Figura 1. Evolução, entre 1945 e 2005, do número de artigos, número de instituições e número de autores atuantes na pesquisa brasileira em erosão do solo.

\footnotetext{
(7) Os artigos obtidos diretamente em formato digital não sofreram nenhum processamento e os obtidos a partir de pesquisa direta em biblioteca foram escanerizados em formato PDF, compondo um anexo digital à dissertação de mestrado que deu origem a este trabalho.
}

(8) A Bragantia só voltaria a publicar três artigos relacionados com a área em 2007. 
levando a resultados práticos em técnicas de controle (cobertura do solo e terraceamento) e na compreensão do processo erosivo. Pode-se dizer que o IAC iniciou, entre 1950 e 1970, a pesquisa brasileira em erosão do solo nas quatro estações experimentais citadas, resultando em artigos de síntese, baseados em longos períodos de experimentação. Os artigos abordaram todos os fatores da erosão conhecidos e representaram uma linha institucional de pesquisa, trabalhando conceitos e métodos que foram replicados em todo o Brasil nas décadas subseqüentes. O grupo de pesquisadores era composto por J. Bertoni, F. Grohmann, J.Q.A. Marques, entre outros (Grohmann \& Catani, 1949; Bertoni, 1949; Alencar, 1952; Verdade et al., 1956; Grohmann et al., 1956; Bertoni, 1959; Marques \& Bertoni, 1961; Marques et al., 1961; Barreto et al., 1961, 1962; Bertoni \& Pastana, 1964; Lombardi-Neto \& Pastana, 1972).

Os dados do quadro 1 evidenciam o pioneirismo da revista Bragantia na publicação de artigos sobre erosão do solo, bem como sua brusca substituição, a partir da década de 1980, pelos periódicos RBCS e PAB. $\mathrm{Na}$ avaliação dos periódicos, observou-se ainda que somente na década de 1990 inicia-se a publicação de artigos em periódicos de edição estrangeira.

A partir do final da década de 1970, o IAC continuou mantendo presença institucional significativa, mas a produção de outros centros de pesquisa passou a ter uma importância relativa maior no conjunto, principalmente de instituições da Região Sul do país, como a UFRGS e o IAPAR, marcando definitivamente os dois pólos geográficos mais representativos quantitativamente em produção de pesquisa brasileira em erosão do solo. As pesquisas realizadas no Estado de São Paulo, representado pelo IAC e mais tarde também pela USP e UNESP, e as pesquisas conduzidas na Região Sul, representadas por UFRGS, FEPAGRO, IAPAR, UFSM e UDESC, dominaram amplamente o conjunto da produção científica. Isso é evidenciado pelos dados do quadro 2 , onde estão listadas instituições de pesquisa ordenadas pelo total de participações em publicações referentes ao tema erosão acelerada do solo ao longo do tempo.

A figura 2 complementa as informações do quadro 2 por meio do histograma da participação das instituições. Enquanto os dados médios mostrados no quadro 2 indicam uma distribuição equilibrada nas últimas duas décadas, o histograma da figura 2 ressalta a concentração das publicações. Aproximadamente metade das instituições tem apenas uma participação em artigos, respondendo por menos de $10 \%$ do total de participações, ao passo que menos de $10 \%$ das instituições concentram mais de $40 \%$ das participações em artigos publicados.

Quadro 1. Evolução do número de artigos sobre erosão do solo publicados em periódicos nacionais e estrangeiros por décadas, entre 1940 e 2000

\begin{tabular}{|c|c|c|c|c|c|c|c|c|}
\hline & \multicolumn{7}{|c|}{ Década } & \multirow{2}{*}{ Total } \\
\hline & 1940 & 1950 & 1960 & 1970 & 1980 & 1990 & 2000 & \\
\hline \multicolumn{9}{|l|}{ Periódicos de edição brasileira } \\
\hline $\begin{array}{l}\text { Bragantia } \\
\text { Brazilian Archives of Biology and Technology }\end{array}$ & 2 & 4 & 5 & 1 & & 2 & $\begin{array}{l}1 \\
2\end{array}$ & $\begin{array}{r}15 \\
2\end{array}$ \\
\hline Pesquisa Agropecuária Brasileira & & & & 1 & 5 & 13 & 11 & 30 \\
\hline Revista Brasileira de Ciência do Solo & & & & 3 & 44 & 42 & 47 & 136 \\
\hline Scientia Agrícola & & & & & & 1 & 6 & 7 \\
\hline Total edição brasileira & 2 & 4 & 5 & 5 & 49 & 58 & 67 & 190 \\
\hline \multicolumn{9}{|l|}{ Periódicos de edição estrangeira } \\
\hline Agriculture, Ecosystems and Environment & & & & & & & 2 & 2 \\
\hline Agronomy for Sustainable Development & & & & & & & 1 & 1 \\
\hline Catena & & & & & & 1 & 1 & 2 \\
\hline Computers \& Geosciences & & & & & & & 2 & 2 \\
\hline Earth Surface Processes and Landforms & & & & & & 1 & 2 & 3 \\
\hline Experimental Agriculture & & & & & & 1 & & 1 \\
\hline Geografiska Annaler & & & & & & 1 & & 1 \\
\hline Hydrological Processes & & & & & & 1 & & 1 \\
\hline Interciencia & & & & & & & 1 & 1 \\
\hline Journal of Irrigation and Drainage Engineering-Asce & & & & & & 1 & 1 & 1 \\
\hline Journal of Radioanalytical and Nuclear Chemistry & & & & & & & 1 & 1 \\
\hline Journal of Soil and Water Conservation & & & & & & 1 & 1 & 2 \\
\hline Land Degradation \& Development & & & & & & & 1 & 1 \\
\hline Landbauforschung Volkenrode & & & & & & & 1 & 1 \\
\hline Radiation Physics and Chemistry & & & & & & & 1 & 1 \\
\hline Soil \& Tillage Research & & & & & & 1 & 3 & 4 \\
\hline Soil Science & & & & & & & 1 & 1 \\
\hline Soil Science Society of America Journal & & & & & & 2 & 4 & 6 \\
\hline Soil use and Management & & & & & & 1 & & 1 \\
\hline Transactions of the Asae & & & & & & & 1 & 1 \\
\hline Tropenlandwirt & & & & & & & 1 & 1 \\
\hline Total de edição estrangeira & & & & & & 11 & 24 & 35 \\
\hline Total & 2 & 4 & 5 & 5 & 49 & 69 & 91 & 225 \\
\hline
\end{tabular}


Outra marca importante da polarização geográfica da pesquisa são as parcerias intra-regionais. No quadro 3 é possível identificar as co-autorias mais encontradas em artigos da pesquisa brasileira em erosão acelerada do solo, ficando claro, por um lado, a tendência das instituições em procurar parceiros dentro

Quadro 2. Principais instituições brasileiras com atuação em pesquisas sobre erosão do solo e o detalhamento da participação em autorias de artigos publicados

\begin{tabular}{|c|c|c|c|c|c|c|c|c|c|c|}
\hline \multirow{2}{*}{ Nome (Sigla) } & \multicolumn{8}{|c|}{ Década } & \multicolumn{2}{|c|}{ Edição } \\
\hline & 1940 & 1950 & 1960 & 1970 & 1980 & 1990 & 2000 & Total & Estrangeira & Nacional \\
\hline $\begin{array}{l}\text { Universidade Federal do Rio Grande do } \\
\text { Sul - UFRGS }\end{array}$ & & & & 3 & 8 & 13 & 18 & 42 & 4 & 38 \\
\hline $\begin{array}{l}\text { Instituto Agronômico de } \\
\text { Campinas - IAC }\end{array}$ & 2 & 4 & 5 & 2 & 8 & 12 & 8 & 41 & 5 & 36 \\
\hline $\begin{array}{l}\text { Universidade de São } \\
\text { Paulo - USP }\end{array}$ & & & & & 6 & 10 & 22 & 38 & 14 & 24 \\
\hline $\begin{array}{l}\text { Empresa Brasileira de Pesquisa } \\
\text { Agropecuária - EMBRAPA }\end{array}$ & & & & 1 & 11 & 16 & 5 & 33 & 2 & 31 \\
\hline $\begin{array}{l}\text { Universidade do Estado de Santa } \\
\text { Catarina - UDESC }\end{array}$ & & & & & 1 & 6 & 16 & 23 & & 23 \\
\hline $\begin{array}{l}\text { Fundação Estadual-RS de Pesquisa } \\
\text { Agropecuária - FEPAGRO }\end{array}$ & & & & 2 & 7 & 7 & 1 & 17 & & 17 \\
\hline $\begin{array}{l}\text { Universidade Estadual Paulista Júlio } \\
\text { de Mesquita Filho Total - UNESP }\end{array}$ & & & & & 2 & 3 & 7 & 12 & & 12 \\
\hline $\begin{array}{l}\text { Instituto Agronômico do } \\
\text { Paraná - IAPAR }\end{array}$ & & & & 1 & 9 & 3 & 1 & 14 & 2 & 12 \\
\hline Universidade Federal da Paraíba - UFPB & & & & & 2 & 7 & 3 & 12 & 1 & 11 \\
\hline $\begin{array}{l}\text { Universidade Federal de Santa } \\
\text { Maria - UFSM }\end{array}$ & & & & & 3 & 2 & 7 & 12 & 2 & 10 \\
\hline $\begin{array}{l}\text { Universidade Federal de } \\
\text { Lavras - UFLA }\end{array}$ & & & & & & 5 & 6 & 11 & & 11 \\
\hline $\begin{array}{l}\text { Universidade Federal Rural de } \\
\text { Pernambuco - UFRPE }\end{array}$ & & & & & 4 & 4 & 3 & 11 & & 11 \\
\hline $\begin{array}{l}\text { Universidade Federal de } \\
\text { Viçosa - UFV }\end{array}$ & & & & & 2 & 3 & 6 & 11 & 2 & 9 \\
\hline $\begin{array}{l}\text { Universidade Federal do } \\
\text { Ceará - UFC }\end{array}$ & & & & & 5 & 1 & 4 & 10 & & 10 \\
\hline Outra & & & & & 13 & 45 & 59 & 117 & 49 & 68 \\
\hline Soma - participações em artigos & 2 & 4 & 5 & 9 & 81 & 137 & 166 & 404 & 81 & 323 \\
\hline Número de instituições & 1 & 1 & 1 & 5 & 23 & 40 & 41 & 65 & 34 & 46 \\
\hline Média (participações em artigos/instituição & 2,0 & 4,0 & 5,0 & 1,8 & 3,5 & 3,4 & 4,0 & 6,2 & 2,4 & 7,0 \\
\hline
\end{tabular}

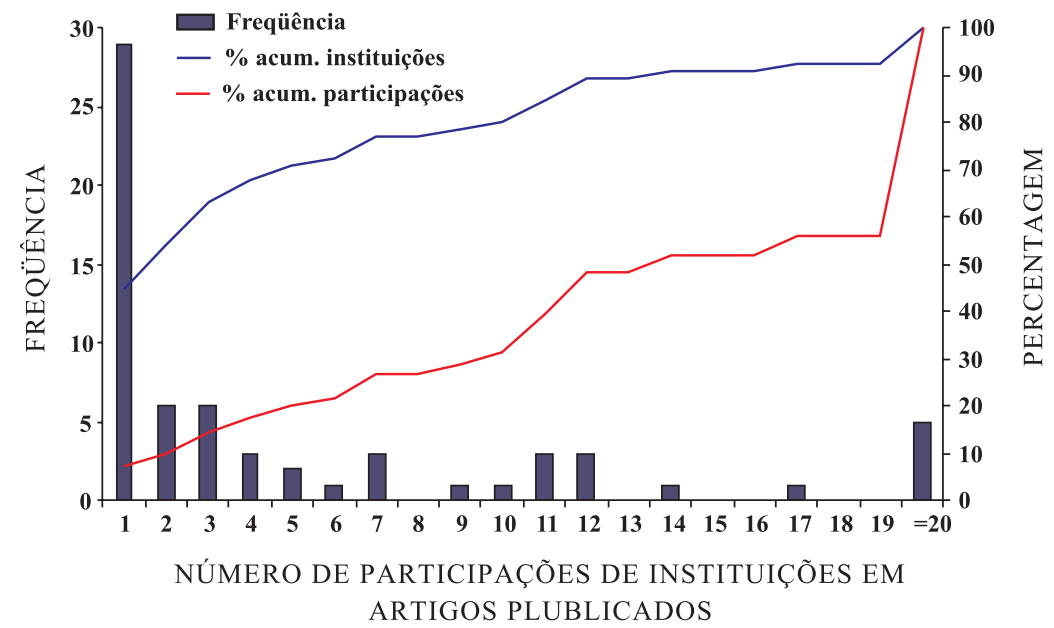

Figura 2. Histograma de participação de instituições em artigos sobre erosão do solo. 
da mesma região e, por outro, indicando existência provável de afinidades temáticas que acompanham as parcerias.

Durante toda a década de 1980, a UFRGS realizou trabalhos focados na comparação de práticas de manejo e tipos de cobertura vegetal, influenciando as perdas de solo e de água. Os experimentos foram montados em parcelas e o uso de simuladores de chuva foi corrente(Eltz et al., 1977; Vieira et al., 1978; Eltz et al., 1984; Lopes et al., 1987; Bertol et al., 1989; Amado et al., 1989). Essa linha foi mantida durante a década de 1990 (Carvalho et al., 1990; Alves et al., 1995; Giasson \& Cassol, 1996, 1999) e até a década de 2000 (Levien \& Cogo, 2001; Morais \& Cogo, 2001; Cogo et al., 2003; Streck \& Cogo, 2003; Volk et al., 2004; Castro et al., 2006), com poucas modificações estruturais, e os artigos foram publicados principalmente na RBCS. N.P. Cogo foi a figura marcante na introdução, no desenvolvimento e na difusão dessa linha de pesquisa na Região Sul, contando com parcerias feitas com pesquisadores do IPRNR, mais tarde vinculado à FEPAGRO. A partir do começo da década de 1990, a UDESC passou a refletir a influência dessa linha em vários artigos (Bertol \& Miquelluti, 1993; Bertol, 1994; Schick et al., 2000; Bertol et al., 2003, 2004a,b, 2005, 2006; Lemos-Mello et al., 2003; Leite et al., 2004; Guadagnin et al., 2005), nos quais Ildegardis Bertol teve participação quantitativa mais relevante. Nesses casos, ênfase maior foi dada à avaliação da relação erosão-perda de nutrientes, mas o contexto das pesquisas foi sempre semelhante à matriz que lhe deu origem.

Paralelamente, a partir da década de 1990, foram desenvolvidos trabalhos na UFRGS que tiveram forte interface com a física do solo e hidráulica do escoamento superficial. Essa linha foi conduzida em parceria entre a UFRGS e a UFSM, envolvendo vários pesquisadores, entre os quais sobressaíram pelo número de participações, E.A. Cassol e J.M. Reichert. A elaboração das pesquisas levou em consideração a subdivisão do processo erosivo em sulcos e entressulcos, conforme as características de fluxo e origem dos sedimentos, procurando abordar, entre outras questões, a relação entre índices de expressão de estabilidade de agregados e erodibilidade dos solos, além de determinar taxas de desagregação e a tensão crítica de cisalhamento, variando o tipo de solo, as práticas de manejo e a cultura (Veiga et al., 1993; Braida \& Cassol, 1996; Albuquerque et al., 2000; Schafer et al., 2001a; Schafer et al., 2001b; Reichert et al., 2001; Cantalice et al., 2003; Cassol et al., 2004). O modelo Water Erosion Prediction Project (WEEP) utiliza esses conceitos, o que ampliou a aplicabilidade dos resultados em estudos de predição, que eram focalizados até então apenas na Equação Universal de Perda de Solo (USLE).

A formação das linhas de pesquisas do Sul e também do Sudeste do país sofreu, em grande medida, a influência dos temas e modelos trabalhados na Universidade de Purdue (EUA), onde pesquisadores brasileiros complementaram a formação de nível superior em programas de pós-graduação. Essa transferência ficou evidente na publicação de artigos em parcerias (Lombardi-Neto \& Moldenhauer, 1992; Veiga et al., 1993; Cogo et al., 1996; Marques et al., 1998; Reichert et al., 2001; Cochrane et al., 2005; Favaretto et al., 2006) e se propagou no Brasil, repetindo o mesmo processo na relação centro-periferia do Sul-Sudeste com instituições de pesquisa do restante do País.

A atração temática pela USLE também ficou evidente. Praticamente todas as instituições ligadas à pesquisa em erosão do solo no Brasil publicaram, em maior ou menor grau, trabalhos ligados ao modelo. O padrão mais replicado de artigos nessa linha foi um tipo de pesquisa voltada à estimação do fator $R$ do modelo USLE com base em séries históricas de estações meteorológicas. A metodologia foi replicada pontualmente para diversas localidades (Lopes \& Brito, 1993; Bertol, 1993, 1994; Albuquerque et al., 1994; Silva et al., 1997a,b; Marques et al., 1998; Roque et al., 2001; Colodro et al., 2002; Dias \& Silva, 2003; Silva \& Dias, 2003; Silva, 2004). Contudo, é no conjunto de artigos publicados na década de 1980 e início da década de 1990, pelo Instituto Agronômico do Paraná (IAPAR), que se observou o esforço mais conseqüente em estimar os fatores do modelo para uma grande extensão territorial (Biscaia et al., 1985; Cataneo et al., 1982; Castro-Filho et al., 1982; Roth et al., 1985; Rufino et al., 1985, 1993; Rufino, 1986). Ainda do Paraná, vale ressaltar a singularidade da contribuição de parcerias envolvendo a UFPR, Embrapa/CNPS, Embrapa/CPAC e, mais recentemente, IAPAR, centralizadas na pessoa de R.A.Dedecek. Os estudos, embora esparsos no tempo, focalizam, na maior parte das vezes, o bioma Cerrado e discutem conseqüências da erosão na degradação de solos e na relação da erosão com a produtividade, utilizando pela primeira vez a simulação de erosão por meio de remoção de camadas de solo (Dedecek et al., 1986; Dedecek, 1987; Rachwal \& Dedecek, 1996; Gaertner et al., 2003).

Como já colocado, a Região Sudeste inaugurou a pesquisa em erosão acelerada do solo com os trabalhos do IAC entre os anos de 1950 e 1970. A partir de então, com o aumento de artigos publicados por outras instituições de pesquisa, logicamente a importância relativa do IAC diminuiu, porém a produção científica manteve-se significativa. Entre 1980 e 2000, o IAC mesclou estudos focados na estimativa de parâmetros da USLE com estudos de avaliação de diferentes condições de manejo, solo e cobertura na produção de sedimentos e enxurrada, muito semelhantes aos praticados na Região Sul (Benatti-Jr. et al., 1977; Dechen et al., 1981, Castro et al., 1986a,b; LombardiNeto et al., 1988; Carvalho et al., 1991; LombardiNeto \& Moldenhauer, 1992; Vieira \& Lombardi-Neto, 1995; Albuquerque et al., 1998; De-Maria \& LombardiNeto, 1997; Nascimento \& Lombardi-Neto, 1999). Fundamental nas contribuições do IAC foi a manutenção de parcelas experimentais com sistema 
Quadro 3. Parcerias mais freqüentes na publicação de artigos sobre erosão acelerada do solo no Brasil

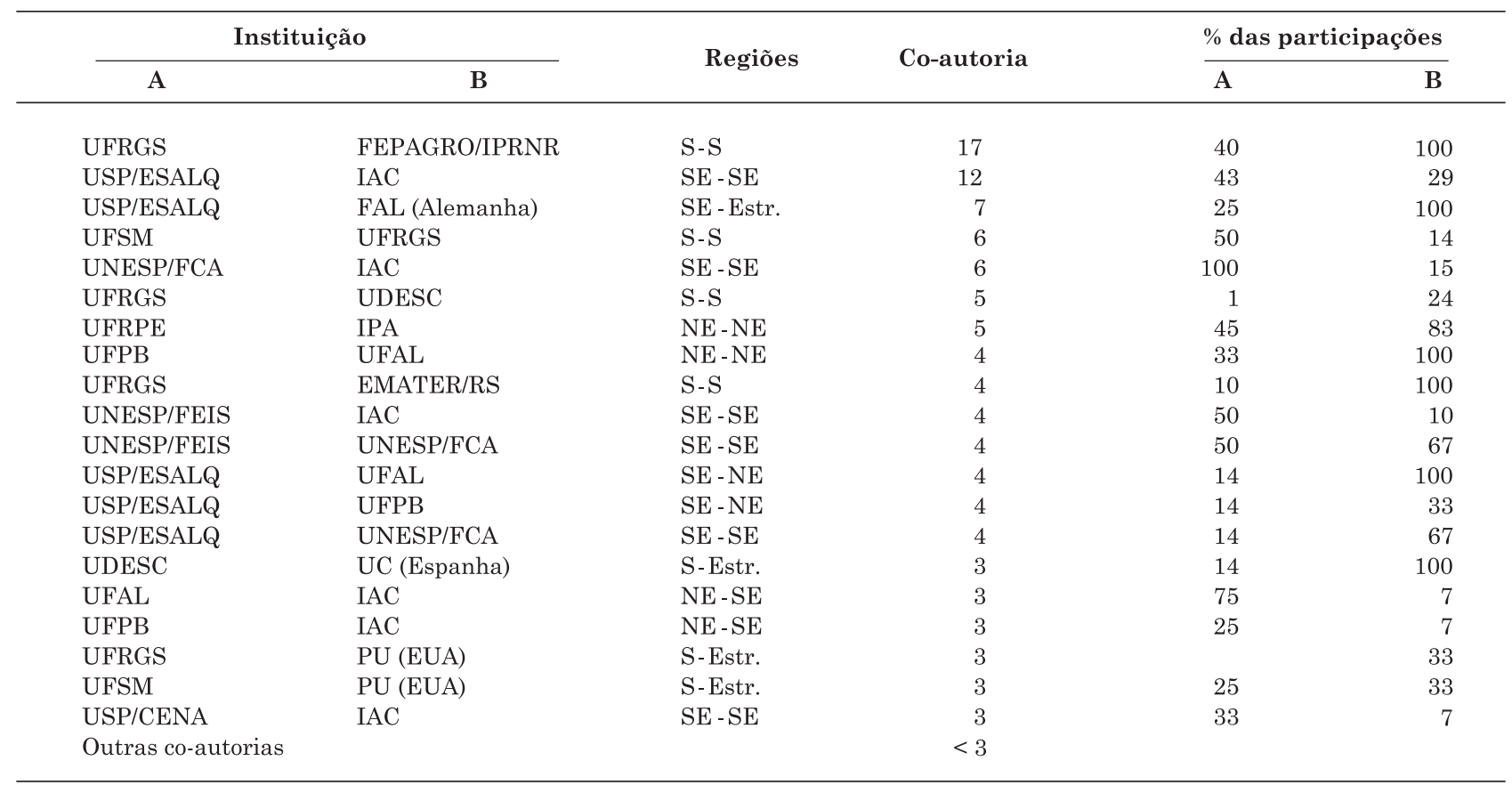

coletor de sedimentos e enxurrada, instaladas em 1943 e 1945, gerando dados continuamente. Esses dados geraram a maior parte dos artigos publicados pelo IAC e, ainda, atendeu a objetivos de grupos de trabalhos internacionais no estudo das relações entre erosão, perda de nutrientes, produtividade e tempo (Tenberg et al., 1997).

A presença da USP na pesquisa brasileira em erosão do solo foi tímida até o fim da década de 1980; os poucos trabalhos publicados respondiam a linhas de pesquisas já traçadas pelos grupos da Região Sul do País ou pelo IAC. A partir de 1990, no entanto, a USP/Esalq deu início a uma seqüência de publicações que se distinguiu por discutir aspectos e conceitos variados em um contexto de planejamento de uso e ocupação da terra no meio rural. Essa linha multifacetada, conduzida, entre outros, por G. Sparovek, começou abordando a relação entre erosão e produtividade, migrando para a discussão do conceito de tolerância à erosão e desenvolvimento de indicadores de risco de degradação (Sparovek et al., 1991, 1993, 1997; Salviano et al., 1998; Ranieri et al., 1998). A partir do ano 2000, esse grupo desenvolveu trabalhos em que incorporou ferramentas de geoprocessamento mescladas a modelos de predição ou estimativa de erosão (USLE, WEEP, ${ }^{137} \mathrm{Cs}$ ) e à discussão de impactos ambientais. Esses trabalhos foram publicados, predominantemente, em periódicos de edição estrangeira (Sparovek et al., 2000, 2001; Sparovek \& Schnug, 2001a,b; Ranieri et al., 2002; Sparovek \& De-Maria, 2003; Bacchi et al., 2003; Jong van-Lier et al., 2005; Correchel et al., 2006). As parcerias nesse conjunto incluíram principalmente a
USP/Cena, que, por sua vez, fez parcerias com a UEL na publicação de artigos utilizando a técnica de ${ }^{137} \mathrm{Cs}$ (Schafer et al., 2001a; Andrello et al., 2001, 2003; Guimarães et al., 2003).

No Sudeste, vale ressaltar, ainda, as pesquisas desenvolvidas nas Universidades de Minas Gerais: UFV e UFLA. A primeira, até o princípio da década de 1990, publicou três ou menos trabalhos, vinculados principalmente ao modelo USLE. A partir da metade da década de 1990, entretanto, um grupo de pesquisa integrado por F.F. Pruski, entre outros, desenvolveu pesquisas em interfaces com engenharia agrícola e física do solo, abordando modelagem de escoamento superficial, cálculo da erosividade da chuva, avaliação de efeitos microestruturais da erosão, entre outros temas (Pruski et al., 1997, 2001; Griebeler et al., 2001, 2005; Schaefer et al., 2002; Nearing et al., 2004; Moreira et al., 2006). Na UFLA, o ritmo de publicação também se intensificou a partir da segunda metade da década de 1990 com os trabalhos de M.L.N. Silva e N. Curi focalizados no desenvolvimento de métodos para estimativa da erodibilidade de solos, publicados na revista PAB (Silva et al., 1994, 1999, 2000; Sá et al., 2004). Essa linha de pesquisa foi ligada ao modelo USLE e teve saliente interface com a física do solo.

A relevância quantitativa de autores das regiões Sul e Sudeste na participação em publicações é mostrada no quadro 4, em que os autores foram ordenados segundo o total de participações em artigos publicados.

À semelhança do que ocorreu com as instituições, o histograma da figura 3 mostra a concentração de mais de $20 \%$ das participações nas autorias de 
artigos em pouco mais de $1 \%$ dos autores relacionados ao tema erosão acelerada do solo. Por outro lado, quase dois terços dos autores tiveram apenas uma participação em artigos publicados. Essa concentração não é verificável pela média geral mostrada no quadro 4 .

Na Região Nordeste do Brasil, foram detectadas quatro principais instituições que desenvolvem pesquisa em erosão do solo: UFRPE, UFPB, UFC e IPA/Embrapa. Ao contrário do que ocorre nas Regiões Sul e Sudeste, aproximadamente 75 \% dos artigos foram publicados antes de 1995. Até essa data, os trabalhos foram pautados pela quantificação de fatores do modelo USLE em diferentes condições de manejo, cobertura e tipo de solo. O exemplo mais conseqüente dessa linha no Nordeste foi uma série de experimentos mantidos por longo prazo pela parceria entre UFRPE e IPA/Embrapa, cujos dados resultaram em vários trabalhos (Margolis et al., 1980, 1985, 1991; NunesFilho et al., 1990; Cantalice \& Margolis, 1993; Silva et al., 1999). Esse conjunto evidencia a perenidade de uma linha institucional de pesquisa conduzida no Nordeste do Brasil, entre outros pesquisadores, por E. Margolis. No mesmo contexto, a UFPB, UFC e UFAL também publicaram trabalhos (Tavora et al., 1985,a,b; Martins-Filho \& Silva, 1985; Silva et al., 1986; Campos-Filho et al., 1991; Campos-Filho et al., 1992; Melo-Filho \& Silva, 1993; Albuquerque et al., 1994), cujo conjunto sugere a influência formativa de linhas de pesquisas desenvolvidas no Sul e Sudeste do país, principalmente na UFRGS, IAPAR, IAC e USP/ Esalq $^{(9)}$.

Quadro 4. Principais autores com atuação em pesquisa sobre erosão do solo, vinculados a instituições brasileiras, e detalhamento da participação em autoria de artigos publicados

\begin{tabular}{|c|c|c|c|c|c|c|c|c|c|c|c|c|}
\hline \multirow{2}{*}{ Nome do autor } & \multicolumn{7}{|c|}{ Década } & \multirow{2}{*}{ Total } & \multicolumn{2}{|c|}{$1^{\circ}$ autor } & \multicolumn{2}{|c|}{ Edição } \\
\hline & 1940 & 1950 & 1960 & 1970 & 1980 & 1990 & 2000 & & Não & Sim & Estrangeira & Nacional \\
\hline Cogo, NP & & & & 2 & 6 & 7 & 9 & 24 & 21 & 3 & 1 & 23 \\
\hline Bertol, I & & & & & 2 & 6 & 15 & 23 & 4 & 19 & & 23 \\
\hline Lombardi Neto, F & & & & 1 & 7 & 8 & 2 & 18 & 15 & 3 & & 18 \\
\hline Cassol, EA & & & & 1 & 3 & 3 & 9 & 16 & 13 & 3 & 1 & 15 \\
\hline Sparovek, G & & & & & & 5 & 10 & 15 & 5 & 10 & 8 & 7 \\
\hline Curi, N & & & & & & 8 & 5 & 13 & 13 & & & 13 \\
\hline Levien, $\mathrm{R}$ & & & & & 4 & 5 & 3 & 12 & 10 & 2 & & 12 \\
\hline Eltz, FLF & & & & 1 & 4 & 2 & 3 & 10 & 6 & 4 & 2 & 8 \\
\hline Silva, JRC & & & & & 5 & 1 & 4 & 10 & 7 & 3 & & 10 \\
\hline De-Maria, IC & & & & & 2 & 1 & 6 & 9 & 8 & 1 & 3 & 6 \\
\hline Dechen, SCF & & & & & 4 & 2 & 2 & 8 & 7 & 1 & 3 & 5 \\
\hline Bertoni, J & 1 & 1 & 5 & 1 & & & & 8 & 5 & 3 & & 8 \\
\hline Carvalho, MP & & & & & 2 & 2 & 4 & 8 & 3 & 5 & & 8 \\
\hline Cataneo, A & & & & & 4 & 3 & 1 & 8 & 7 & 1 & & 8 \\
\hline Dedecek, RA & & & & 1 & 4 & 2 & 1 & 8 & 3 & 5 & & 8 \\
\hline Silva, MLN & & & & & & 4 & 4 & 8 & 3 & 5 & & 8 \\
\hline Schnug, E & & & & & & 1 & 6 & 7 & 7 & & 6 & 1 \\
\hline Pruski, FF & & & & & & 1 & 6 & 7 & 5 & 2 & 2 & 5 \\
\hline Reichert, JM & & & & & & 1 & 6 & 7 & 6 & 1 & 1 & 6 \\
\hline De Lima, JM & & & & & & 4 & 3 & 7 & 6 & 1 & & 7 \\
\hline Ferreira, MM & & & & & & 3 & 3 & 6 & 6 & & & 6 \\
\hline Guadagnin, JC & & & & & & & 6 & 6 & 5 & 1 & & 6 \\
\hline Margolis, E & & & & & 3 & 3 & & 6 & 3 & 3 & & 6 \\
\hline Vieira, SR & & & & & 3 & 2 & 1 & 6 & 5 & 1 & & 6 \\
\hline Outros & 2 & 7 & 8 & 6 & 91 & 131 & 221 & 466 & 319 & 147 & 104 & 362 \\
\hline $\begin{array}{l}\text { Soma } \\
\text { (participações em artigos) }\end{array}$ & 3 & 8 & 13 & 13 & 144 & 205 & 330 & 716 & 492 & 224 & 131 & 585 \\
\hline Número de autores & 3 & 5 & 5 & 12 & 74 & 128 & 168 & 316 & 245 & 130 & 91 & 252 \\
\hline $\begin{array}{l}\text { Média (participações } \\
\text { em artigos/autor) }\end{array}$ & 1,0 & 1,6 & 2,6 & 1,1 & 1,9 & 1,6 & 1,9 & 2,2 & 2,0 & 1,7 & 1,4 & 2,3 \\
\hline Número (artigos) & 2 & 4 & 5 & 5 & 49 & 69 & 91 & 225 & & & 35 & 190 \\
\hline Média (artigos/autor) & 0,7 & 0,8 & 1,0 & 0,4 & 0,7 & 0,5 & 0,5 & 0,7 & & & 0,4 & 0,8 \\
\hline
\end{tabular}

${ }^{(9)}$ Por outro lado, extraem-se do conjunto de publicações das instituições sediadas no Nordeste do Brasil, artigos que demonstram diversidade temática e metodológica. A avaliação de impactos ambientais causados pela erosão foi já em 1985 estudada em um artigo da UFC (Silva \& Paiva, 1985). Do mesmo modo, há um artigo de discussão de métodos de definição de tolerância à erosão para os solos de Pernambuco (Galindo \& Margolis, 1989) e, recentemente, a UFPB e UFPE descreveram o efeito em longo prazo da erosão na perda de nutrientes e carbono em diferentes usos da terra (Fraga \& Salcedo, 2004). 


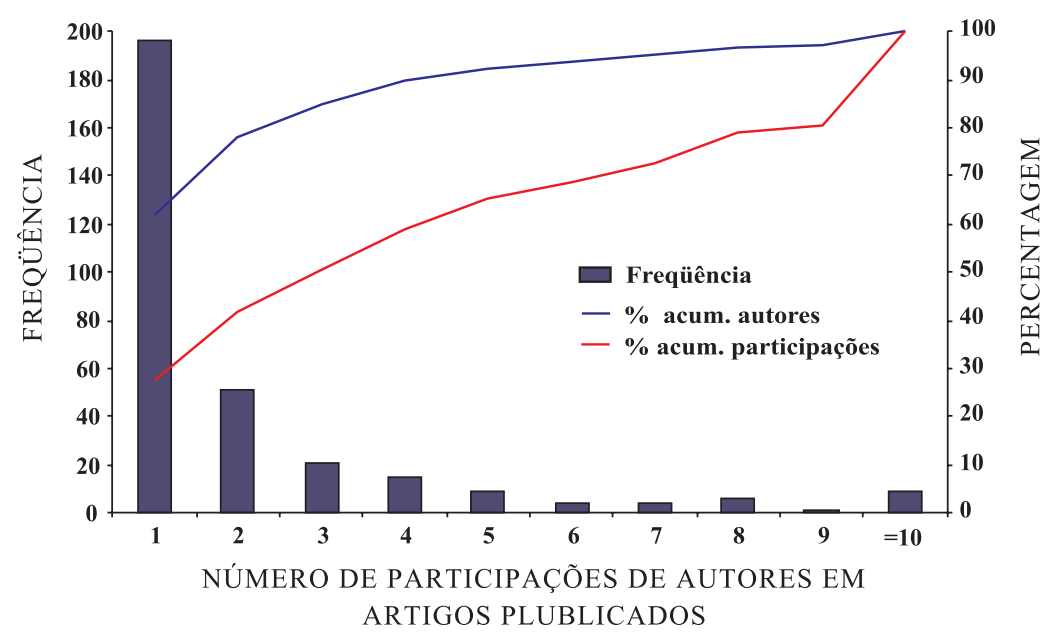

Figura 3. Histograma de participação de autores em artigos publicados sobre erosão do solo.

No quadro 5 foram tabulados os dados das categorias "Sujeito" e "Objetivo" do cadastro temático do banco de dados, que definiram sinteticamente o objeto que o trabalho em questão focalizou, a escala em que o trabalho foi desenvolvido e em que âmbito a finalidade do trabalho esteve inserida ${ }^{(10)}$. Esse resumo aponta, justamente, uma homogeneidade temática e metodológica dos trabalhos. Apesar de portarem diferenças intrínsecas aos seus objetivos específicos, grande porção dos trabalhos se encaixa em padrões moldados até o começo da década de 1980.

Conforme quadro 5 , quase $80 \%$ das pesquisas foram baseadas em estudos pontuais efetuadas em parcelas experimentais (item Escala + Pontual $=78 \%$ ); dois terços das pesquisas enfocaram os efeitos do uso ou cobertura do solo na erosão (item Fator+Uso da terra $=67 \%$ ); e aproximadamente a metade objetivou práticas de controle ligadas à cobertura ou manejo do solo (item Controle+Práticas de cobertura $=43 \% \mathrm{e}$ item Impacto+Físico $=61 \%$ ). Esses itens, quando selecionados no mesmo artigo (ver nota 25), correspondem a um tipo de trabalho cuja temática é quantificar a produção de água e sedimentos em parcelas em função de usos, manejos ou práticas de controle, sob um enfoque eminentemente agrícola. Outro tipo de estudo muito freqüente a partir da década de 1980 foi aquele ligado ao modelo USLE de predição

\footnotetext{
${ }^{(10)}$ Ressalta-se que a regra de preenchimento do cadastro não é exclusiva dentro de cada uma das categorias. Dessa forma, um mesmo artigo pode constar na contagem de dois ou mais ítens e a soma dentro de cada categoria não equivale ao número de artigos e sim ao número de vezes em que o item foi selecionado, de tal maneira que trabalhos de maior variedade metodológica ou variedade de objetivos tendem a ser contados mais vezes. Por esta razão, os subtotais foram omitidos. Por outro lado, a importância relativa de cada ítem pode ser avaliada com relação ao total de artigos conforme os dados das últimas duas colunas dessa tabela.
}

de erosão, somando quase $40 \%$ dos artigos compilados na base de dados (item Predição+USLE = $39 \%$ ).

Por outro lado, foram relativamente poucos os trabalhos que relacionaram erosão e produtividade (item Impacto+Agronômico $=11 \%$ ); avaliaram impactos indiretos da erosão (item Impacto+Ambiental $=4 \%$ ); desenvolveram o conceito de tolerância à erosão (item: Fator+Tolerância $=7 \%$ ); ou que estudaram a erosão do solo em escalas de microbacia hidrográficas (item Escala+Microbacia $=10 \%$ ).

Houve, portanto, no Brasil, uma concentração temática e geográfica da pesquisa, cujo efeito quantitativo na produção científica foi atestado pelos dados dos quadros 1, 2, 4 e 5 e cujo desenho geográfico está ilustrado na seqüência de mapas multitemporais das figuras 4,5 e 6 . O primeiro conjunto (Figura 4) traz a evolução da origem (sedes) em que foram conduzidas as pesquisas publicadas como artigos. O segundo conjunto (Figura 5) adiciona, ao primeiro, a origem das instituições que participaram na autoria dos artigos. Por fim, o terceiro conjunto de mapas (Figura 6) aponta a origem dos dados primários utilizados nas pesquisas. Nos três casos, a referência geográfica foi o município das instituições ou da coleta de dados.

A partir dos mapas das figuras 4, 5 e 6, foi possível evidenciar: a origem dos primeiros pontos de pesquisa nos Estados de São Paulo e Rio Grande do Sul antes da década de 1980 e a permanente centralização da pesquisa no Sul e Sudeste até a década de 2000; a difusão relevante da pesquisa para os estados do Nordeste já na década de 1980 para o restante das Regiões Sudeste e Sul nas décadas de 1990 e 2000; a pequena participação de instituições sediadas na Região Centro-Oeste e a quase ausência da Região Norte no conjunto de pesquisa publicado sobre erosão acelerada do solo; e a concentração da coleta de dados em torno dos centros geográficos das instituições, resultando, provavelmente, em grandes extensões territoriais cujas condições de meio físico e relações com a erosão não foram ainda estudadas. 
Quadro 5. Resumo das categorias "Sujeito" e "Objetivo" do cadastro temático do banco de dados, indicando o número de artigos em que cada item foi tratado

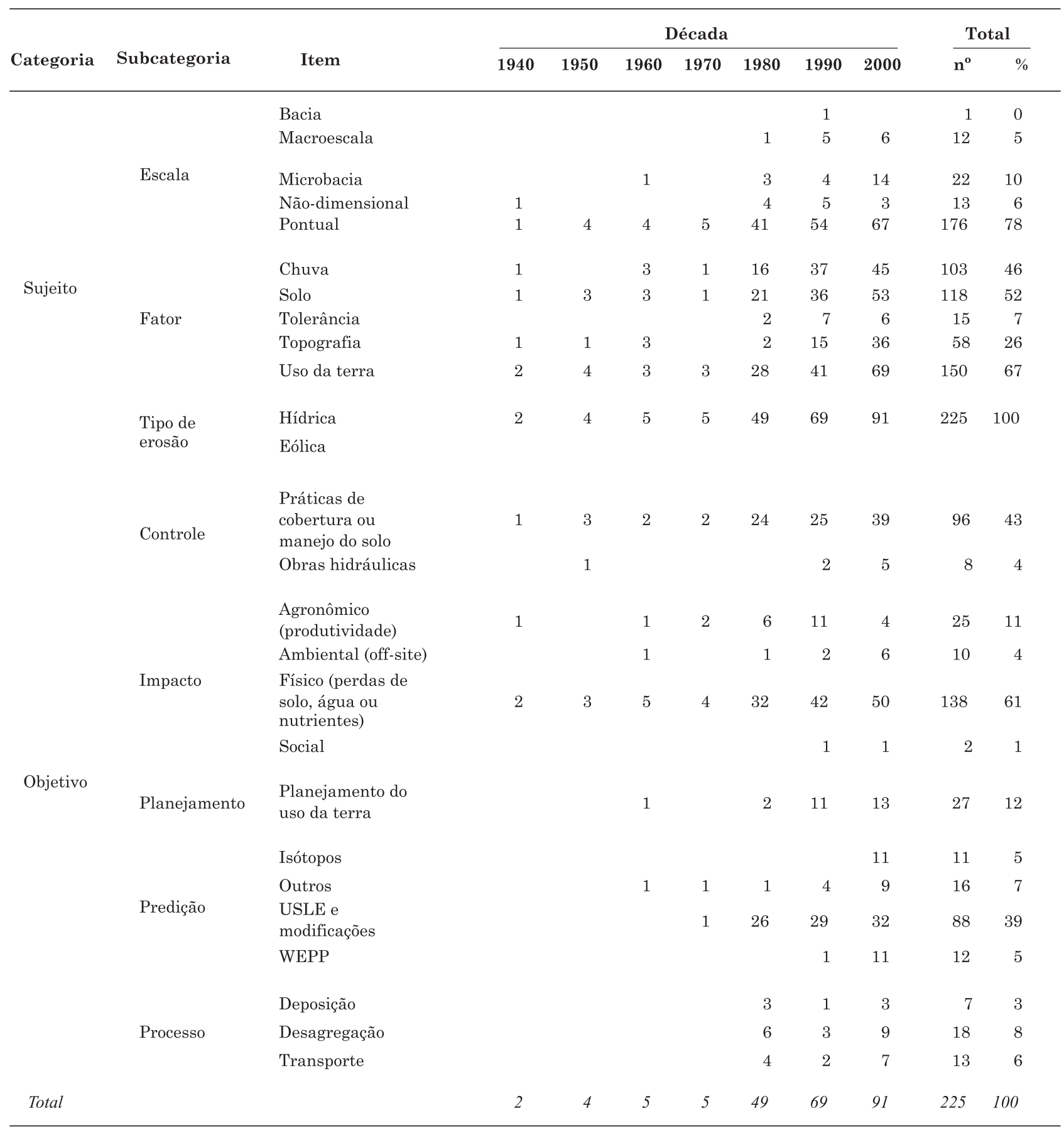

\section{CONCLUSÕES}

1. A pesquisa científica brasileira em erosão acelerada do solo teve uma formação recente.

2. Apesar dos primeiros trabalhos terem sido publicados ainda na década de 1940, aproximadamente metade da produção originou-se nos últimos quinze anos.
3. Houve concentração autoral (autores) e institucional (instituições) na participação em artigos publicados.

4. Cerca de $1 \%$ dos autores foram responsáveis por $20 \%$ das participações; e menos de $10 \%$ das instituições concentraram mais de $40 \%$ das participações em artigos publicados. Aproximadamente metade dos autores e instituições participaram apenas uma 

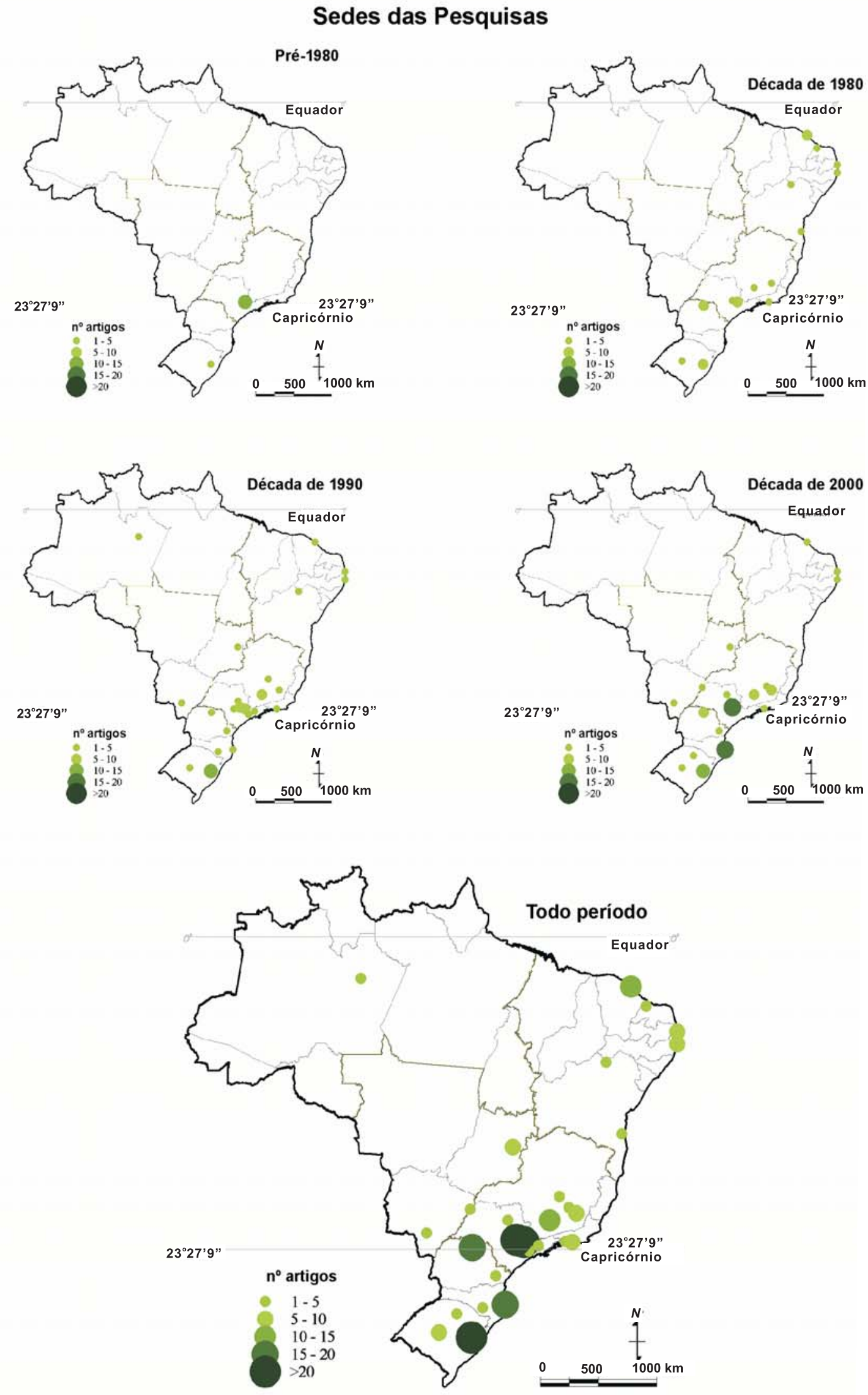

Figura 4. Sedes das pesquisas que resultaram em artigos publicados sobre erosão do solo no Brasil. 


\section{Participação de Instituições}
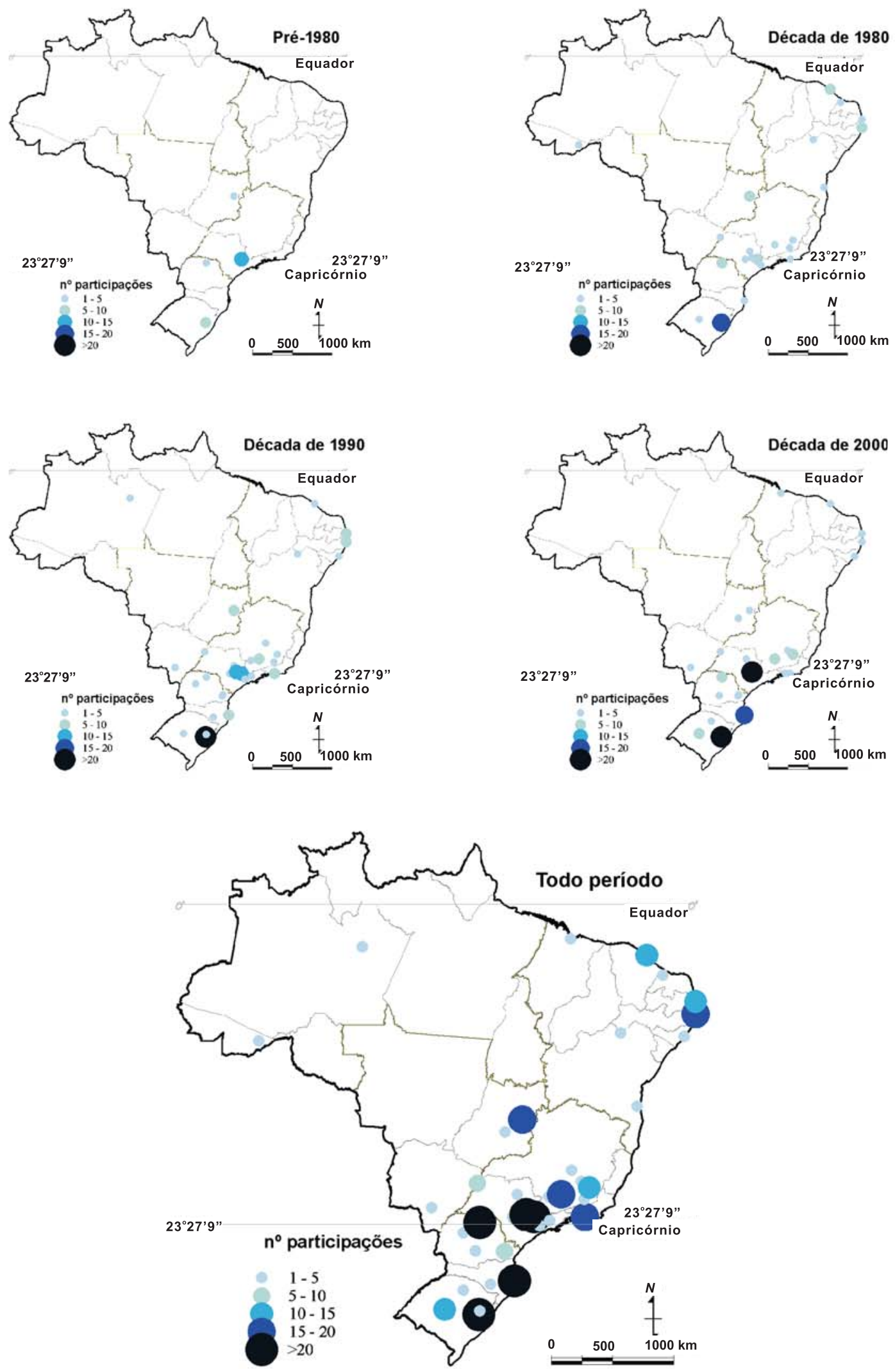

Figura 5. Instituições onde trabalhavam os autores de artigos publicados sobre erosão do solo no Brasil. 


\section{Origem dos Dados das Pesquisas}
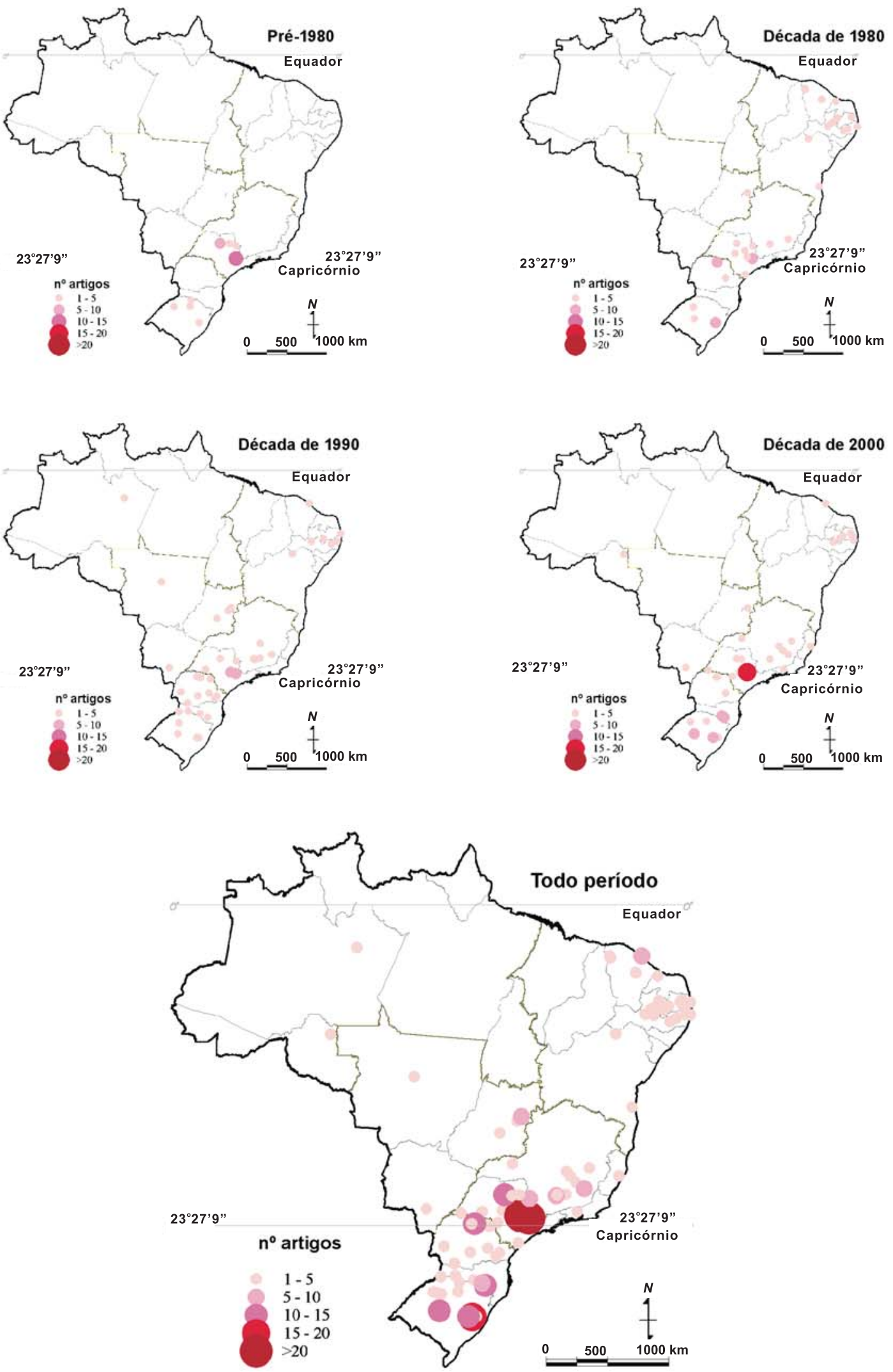

Figura 6. Origem dos dados primários utilizados nas pesquisas sobre erosão do solo no Brasil. 
vez na publicação de artigos científicos em erosão acelerada do solo

5. Houve centralização geográfica na formação de linhas de pesquisa e concentração quantitativa da produção.

6. A formação de linhas de pesquisa bem como a produção científica foi concentrada em instituições da Região Sul e Sudeste, seguidas em menor intensidade por instituições da Região Nordeste. As instituições das Regiões Centro-Oeste e Norte praticamente não focalizaram, até agora, o tema.

7. A pesquisa em erosão do solo foi regionalizada.

8. As instituições tenderam a desenvolver pesquisas cujos dados foram gerados próximos aos seus centros de origem. Isso sugere que há grandes porções territoriais cujas condições de meio físico foram pouco abordadas pela pesquisa em erosão do solo, principalmente nas Regiões Norte e Centro-Oeste do Brasil.

9. Houve concentração temática na pesquisa.

10. Aproximadamente um terço dos artigos tiveram o objetivo central de comparar condições de manejo e culturas agrícolas na produção de sedimentos e enxurrada, visando sobretudo desenvolver técnicas de minimização da erosão em um contexto agrícola.

11. Aproximadamente um terço dos artigos foram relacionados ao modelo USLE de predição de erosão quer seja na sua aplicação, quer seja na estimativa de seus parâmetros.

\section{LITERATURA CITADA}

ALBUQUERQUE, A.W.; CATANEO, A.; LOMBARDI-NETO, F. \& SRINIVASAN, V.S. Parâmetros erosividade da chuva e da enxurrada correlacionados com as perdas de solo de um solo Bruno não-cálcico vértico em Sumé (PB). R. Bras. Ci. Solo, 22:743-749, 1998.

ALBUQUERQUE, A.W.; CHAVES, I.B. \& VASQUES-FILHO, J. Características físicas da chuva correlacionadas com as perdas de solo num regossolo eutrófico de Caruaru (PE). R. Bras. Ci. Solo, 18:279-283, 1994.

ALBUQUERQUE, J.A.; CASSOL, E.A. \& REINERT, D.J. Relação entre a erodibilidade em entressulcos e a estabilidade de agregados. R. Bras. Ci. Solo, 24:141-151, 2000.

ALENCAR, F.M.A. Plantas úteis para revestimento do solo. Bragantia, 12:321-336, 1952.

ALVES, A.G.C.; COGO, N.P. \& LEVIEN, R. Relações da erosão do solo com a persistência da cobertura vegetal morta. R. Bras. Ci. Solo, 19:127-132, 1995.

AMADO, T.J.C.; COGO, N.P. \& LEVIEN, R. Eficácia relativa do manejo do resíduo cultura da soja na redução das perdas de solo por erosão hídrica. R. Bras. Ci. Solo, 13:251257, 1989.
ANDRELlO, A.C.; APPOLONI, C.R.; GUIMARÃES, M.F. \& NASCIMENTO-FILHO, V.F. Use of Cesium-137 Methodology in the evaluation of superficial erosive processes. Braz. Arch. Biol. Technol., 46:307-314, 2003.

ANDRELLO, A.C.; APPOLONI, C.R.; GUIMARÃES, M.F. \& PARREIRA, O.S. A preliminary survey of soil erosion in a small basin in the Paraná State by using $137 \mathrm{Cs}$ methodology. Radiat. Phys. Chem., 61:635-636, 2001.

BACCHI, O.O.S.; REICHARDT, K. \& SPAROVEK, G. Sediment spatial distribution evaluated by three methods and its relation to some soil properties. Soil Tillage Res., 69:117-125, 2003

BARRETO, G.B.; BERTONI, J. \& FORSTER, R. Perdas de terra e água em canais não vegetados. Bragantia, 20:25$28,1961$.

BARRETO, G.B.; BERTONI, J. \& FORSTER, R. Estudo da bacia hidrográfica da barragem Monjolinho. Bragantia, 21:765-777, 1962.

BENATTI-JR, R.; BERTONI, J. \& MOREIRA, C.A. Perdas por erosão em plantio direto e convencional de milho em dois solos do estado de são paulo. R. Bras. Ci. Solo, 1:121-123, 1977.

BERTOL, I. Erosão hídrica em cambissolo húmico distrófico sob diferentes preparos do solo e rotação de cultura. R. Bras. Ci. Solo, 18:267-271, 1994.

BERTOL, I. Índice erosividade (EI30) para Lages (SC). $1^{\text {a }}$ aproximação. Pesq. Agropec. Bras., 28:515-521, 1993.

BERTOL, I. Avaliação da erosividade da chuva na localidade de Campos Novos (SC) no período de 1981-1990. Pesq. Agropec. Bras., 29:1453-1458, 1994.

BERTOL, I.; AMARAL, A.J.; BARBOSA, F.T.; CASSOL, E.A. \& GUADAGNIN, J.C. Perdas de fósforo e potássio por erosão hídrica em um inceptisol sob chuva natural. R. Bras. Ci. Solo, 28:485-494, 2004.

BERTOL, I.; AMARAL, A.J.; BRIGNONI, L.F.; GONZÁLES, A.P. \& GUADAGNIN, J.C. Soil tillage, water erosion, and calcium, magnesium and organic carbon losses. Sci. Agríc., 62:578-584, 2005.

BERTOL, I.; CARRAFA, M.R.; GUADAGNIN, J.C.; LEMOSMELLO, E. \& ZAPAROLLI, A.L.V. Nutrient losses by water erosion. Sci. Agríc., 60:581-586, 2003.

BERTOL, I.; COGO, N.P.; GONZÁLES, A.P. \& VASQUEZ, E.V. Parâmetros relacionados com a erosão hídrica sob taxa constante da enxurrada, em diferentes métodos de preparo do solo. R. Bras. Ci. Solo, 30:715-722, 2006.

BERTOL, I.; COGO, N.P. \& LEVIEN, R. Cobertura morta e metodos de preparo do solo na erosão hídrica em solo com crosta superficial. R. Bras. Ci. Solo, 13:373-379, 1989.

BERTOL, I.; GUADAGNIN, J.C.; LEITE, D. \& RITTER, S.R. Erosão hídrica em um nitossolo háplico submetido a diferentes sistemas de manejo sob chuva simulada. II perdas de nutrientes e carbono orgânico. R. Bras. Ci. Solo, 28:1045-1054, 2004. 
BERTOL, I. \& MIQUELLUTI, D.J. Perdas de água, solo e nutrientes reduzidas pela culltura do milho. Pesq. Agropec. Bras., 28:1205-1213, 1993.

BERTONI, J. Sistemas coletores para determinações de perdas por erosão. Bragantia, 9:147-155, 1949

BERTONI, J. O espaçamento de terraços em culturas anuais determinado em função das perdas por erosão. Bragantia, 19:113-140, 1959.

BERTONI, J. \& PASTANA, F.I. Relação chuva-perdas por erosão em diferentes tipos de solo. Bragantia, 23:3-11, 1964.

BISCAIA, R.M.; HENKLAIN, J.C. \& RUFINO, R.L. Cálculo de erodibilidade (fator K) de dois solos do estado do Paraná R. Bras. Ci. Solo, 5:183-186, 1981.

BRAIDA, J.A. \& CASSOL, E.A. Erodibilidade em sulcos e em entressulcos de um podzólico vermelho-escuro francoarenoso. R. Bras. Ci. Solo, 20:127-134, 1996.

BRAIDA, J.A. \& CASSOL, E.A. Relações da erosão em entressulcos com o tipo e com a quantidade de resíduo vegetal na superfície do solo. R. Bras. Ci. Solo, 23:711$721,1999$.

CAMPOS-FILHO, O.R.; ANDRADE, A.P.; LEPRUN, J.C. \& SILVA, I.F. Erosividade da chuva e erodibilidade do solo no agreste de pernambuco. R. Bras. Ci. Solo, 27:13631370, 1992.

CAMPOS-FILHO, O.R.; ANDRADE, A.P.; LEPRUN, J.C. \& SILVA, I.F. Avaliação de perdas de solo e de água num Podzólico Vermelho-Amarelo Orto do agreste de Pernambuco. Pesq. Agropec. Bras., 26:1057-1062, 1991.

CANTALICE, J.R.B. \& MARGOLIS, E. Características das chuvas e correlação de índices de erosividade com as perdas de solo do agreste de Pernambuco. R. Bras. Ci. Solo, 17:275-281, 1993.

CARVAlHO, F.L.C.; COGO, N.P. \& LEVIEN, R. Eficácia relativa de doses e formas de manejo do resíduo cultural de trigo na redução da erosão hídrica do solo. R. Bras. Ci. Solo, 14227-234, 1990.

CARVALHO, M.P.; CATANEO, A. \& LOMBARDI-NETO, F. Índice KE $>25$ para análise da erosividade da chuva de Mococa (SP). R. Bras. Ci. Solo, 15:375-381, 1991.

CASSOL, E.A.; CANTALICE, J.R.B.; MONDARDO, A. \& REICHERT, J.M. Escoamento superficial e desagregação do solo em entressulcos em solo franco-argilo-arenoso com resíduos vegetais. Pesq. Agropec. Bras., 39:685-690, 2004.

CASTRO, L.G.; COGO, N.P. \& VOLK, L.B.S. Alterações na rugosidade superficial do solo pelo preparo e pela chuva e sua relação com a erosão hídrica. R. Bras. Ci. Solo, 30:339$352,2006$.

CASTRO, O.M.; DECHEN, S.C.F.; DE-MARIA, I.C.; LOMBARDI-NETO, F.; QUAGGIO, J.A. \& VIEIRA, S.R Perdas por erosão de nutrientes vegetais na sucessão soja/trigo em diferentes sistemas de manejo. R. Bras. Ci. Solo,10293-297, 1986a.
CASTRO, O.M.; DECHEN, S.C.F.; LOMBARDI-NETO, F. \& VIEIRA, S.R. Sistemas convencionais e reduzidos de preparo de solo e as perdas por erosão. R. Bras. Ci. Solo, 10:167-171, 1986b.

CASTRO-FILHo, C.; BISCAIA, R.M. \& CATANEO, A. Utilização da metodologia de Wilkinson para cálculo do potencial erosivo das chuvas em cinco localidades do Paraná. R. Bras. Ci. Solo, 6240-241, 1982.

CATANeO, A.; ACQUAROLE, R.M. \& CASTRO-FILHO, C. Programa para cálculo de índices de erosividade de chuvas. R. Bras. Ci. Solo, 6:236-239, 1982.

COCHRANE, B.H.W.; ELTZ, F.L.F.; NORTON, L.D. \& REICHERT, J.M. Controlling soil erosion and Runoff with Polyacrylamide and phosphogypsum on subtropical soil. Trans. Am. Soc. Agron. Eng., 48:149-154, 2005.

COGO, N.P.; FOSTER, G.R. \& MOLDENHAUER, W.C. Flow rates-soil erosion relationship as affected by wheat residue cover: An attempt do define slope lenght limits for conservation tillage. R. Bras. Ci. Solo, 20:475-483, 1996.

COGO, N.P.; LEVIEN, R. \& SCHWARZ, R.A. Perdas de solo e água por erosão hídrica influenciadas por métodos de preparo, classes de declive e níveis de fertilidade do solo. R. Bras. Ci. Solo, 27:743-753, 2003.

COLODRO, G.; CARVALHO, M.P.; PRADO, R.M. \& ROQUE, C.G. Erosividade da chuva: Distribuição e correlação com a precipitação pluviométrica de Teodoro Sampaio (SP). R. Bras. Ci. Solo, 26:809-818, 2002.

CORRECHEL, V.; BACCHI, O.O.S.; DECHEN, S.C.F.; DEMARIA, I.C. \& REICHARDT, K. Erosion rates evaluated by the $137 \mathrm{Cs}$ technique and direct measurements on longterm runoff plots under tropical conditions. Soil Tillage Res., 86:199-208, 2006.

DECHEN, S.C.F.; CASTRO, O.M. \& LOMBARDI-NETO, F. Gramíneas e leguminosas e seus restos culturais no controle da erosão em latossolo roxo. R. Bras. Ci. Solo, 5:133-137, 1981.

DEDECEK, R.A. Efeito das perdas e deposições de camadas de solo na produtividade de um Latossolo VermelhoEscuro dos cerrados. R. Bras. Ci. Solo, 11:323-328, 1987.

DEDECEK, R.A.; DE-FREITAS JR., E. \& RESCK, D.V.S. Perdas de água solo e nutrientes por erosão em Latossolo Vermelho-Escuro dos Cerrados em diferentes cultivos sob chuva natural. R. Bras. Ci. Solo, 10:265-272, 1986.

DE-MARIA, I.C. \& LOMBARDI-NETO, F. Razões de perda de solo e Fator C para sistemas de manejo da cultura do milho. R. Bras. Ci. Solo, 21:263-270, 1997.

DIAS, A.S. \& SILVA, J.R.C. A erosividade das chuvas em Fortaleza (CE). II distribuição, probabilidade de ocorrênciae período de retorno - 1a aproximação. R. Bras. Ci. Solo, 27:335-345, 2003.

ELTZ, F.L.F.; CASSOL, E.A.; GUERRA, M. \& SCOPEL, E. Perdas de solo e água por erosão em diferentes sistemas de manejo e coberturas vegetais em solo laterítico brunoavermelhado distrófico (são jerônimo) sob chuva natural. R. Bras. Ci. Solo, 8117-125, 1984. 
ELTZ, F.L.F.; COGO, N.P. \& MIELNICZUK, J. Perdas por erosão em diferentes manejos de solo e cobertura vegetais em solo laterítico bruno avermelhado distrófico (São Jerônimo). I Resultados do primeiro ano. R. Bras. Ci. Solo, 1:123-127, 1977.

FAVARETTO, N.; BROUDER, S.M.; JOERN, B.C. \& NORTON, L.D. Gypsum Amendment and exchangeable Calcium and Magnesium affecting Phosphorus and Nitrogen in Runoff. Soil Sci. Soc. Am. J., 70:1788-1796, 2006 .

FRAGA, V.S. \& SALCEDO, I.H. Declines of organic nutrient pools in Tropical Semi-Arid Soils under subsistence farming. Soil Sci. Soc. Am. J., 68:215-224, 2004.

GAERTNER, C.; BISCAIA, R.M. \& DEDECEK, R.A. Produtividade de trigo e soja em Latossolo Vermelho distrófico sob erosão simulada e causada pela chuva. Pesq. Agropec. Bras., 38:1443-1449, 2003.

GALINDO, I.C.L. \& MARGOLIS, E. Tolerância de perdas por erosão para solos do estado de Pernambuco. R. Bras. Ci. Solo, 13:95-100, 1989.

GIASSON, E. \& CASSOL, E.A. Relações da erosão em sulcos com vazões aplicadas e doses de resíduos de trigo incorporados a um plintossolo franco-argiloarenoso. R. Bras. Ci. Solo, 20:117-125, 1996.

GREENLAND, D.J. Inaugural Russell memorial lecture: Soil conditions and plant growth. Soil Use Manag., 13:169177,1997

GRIEBELER, N.P.; MARTINS JUNIOR, D.; PRUSKI, F.F. \& SILVA, D.D. Avaliação de um modelo para estimativa da lâmina máxima de escoamento superficial. R. Bras. Ci. Solo, 25:411-417, 2001.

GRIEBELER, N.P.; PRUSKI, F.F.; RAMOS, M.M.; SILVA, D.D \& SILVA, J.M.A. Modelo para a determinação do espaçamento entre desaguadouros em estradas não pavimentadas. R. Bras. Ci. Solo, 29:397-405, 2005.

GROHMANN, F.; MARQUES, J.Q.A. \& VERDADE, F.C. Perdas de elementos nutritivos pela erosão. Elementos minerais e carbono. Bragantia, 15:361-371, 1956.

GROHMANN, F. \& CATANI, R.A. O empobrecimento causado pela erosão e pela cultura algodoeira no solo de Arenito Bauru. Bragantia, 9:125-132, 1949.

GUADAGNIN, J.C.; AMARAL, A.J.; BERTOL, I. \& CASSOL, P.C. Perdas de solo, água e nitrogênio por erosão hídrica em diferentes sistemas de manejo. R. Bras. Ci. Solo, 29:277-286, 2005.

GUIMARÃES, M.F.; NASCIMENTO-FILHO, V.F. \& RITCHIE, J. Application of cesium-137 in a study of soil erosion and deposition in southeastern Brazil. Soil Sci., 168:45-53, 2003.

HARTEMINK, A.E. Publish or perish: How much we write. Bull. Intern. Union Soil Sci., 96:16-23, 1999.

HARTEMINK, A.E. Developments and trends in soil science. 100 volumes of Geoderma (1967-2001). Geoderma, 100:217-268, 2001.
LEITE, D.; BERTOL, I.; GUADAGNIN, J.C.; RITTER, S.R. \& SANTOS, E.J. Erosão hí-drica em um nitossolo háplico submetido a diferentes sistemas de manejo sob chuva simulada. I perdas de solo e Água. R. Ci. Solo, 28:10331044, 2004.

LEMOS-MELLO, E.; BERTOL，I.; CARRAFA, M.R. \& ZAPAROLLI, A.L.V. Perdas de solo e água em diferentes sistemas de manejo de um nitossolo háplico submetido à chuva simulada. R. Bras. Ci. Solo, 27:901-909, 2003.

LEVIEN, R. \& COGO, N.P. Erosão na cultura do milho em sucessão à aveia preta e pousio descoberto, em preparo convencional e plantio direto, com tração animal e tratorizada. R. Bras. Ci. Solo, 25:683-692, 2001.

LEVIEN, R.; COGO, N.P. \& ROCKENBACH, C.A. Erosão na cultura do milho em diferentes sistemas de cultivo anterior e métodos de preparo do solo. R. Bras. Ci. Solo, 14:73-80, 1990.

LOMBARDI-NETO, F.; CASTRO, O.M.; DECHEN, S.C.F.; DEMARIA, I.C. \& VIEIRA, S.R. Efeito de resíduos culturais de milho nas perdas de solo e água. R. Bras. Ci. Solo, 12:71-75, 1988

LOMBARDI-NETO, F. \& MOLDENHAUER, W.C. Erosividade da chuva: Sua distribuição e relação com as perdas de solo em Campinas (SP). Bragantia, 51:189-196, 1992.

LOMBARDI-NETO, F. \& PASTANA, F.I. Relação chuva-perdas por erosão. Bragantia, 31:227-234, 1972.

LOPES, P.R.C. \& BRITO, L.T.L. Erosividade da chuva no médio São Francisco. R. Bras. Ci. Solo, 17:129-133, 1993.

LOPES, P.R.C.; CASSOL, E.A. \& COGO, N.P. Influência da cobertura vegetal morta na redução da velocidade de enxurrada e na distribuição de tamanho de sedimentos transportados. R. Bras. Ci. Solo, 11:193-197, 1987.

LOPES, P.R.C.; COGO, N.P. \& LEVIEN, R. Eficácia relativa de tipos de resíduos culturais espalhados uniformemente sobre o solo na redução da erosão hídrica. R. Bras. Ci. Solo, 1171-75, 1987.

MARGOLIS, E.; ANDRADE, J.E.P.; NETTO, A.V.M. \& SILVA, A.B. Efeito do estádio de desenvolvimento da cultura do milho sobre as perdas por erosão. R. Bras. Ci. Solo, 4:193195,1980

MARGOLIS, E.; GALINDO, I.C.L. \& NETTO, A.V.M. Comportamento de sistemas de cultivo da mandioca em relação à produção e às perdas por erosão. R. Bras. Ci. Solo, 15:357-362, 1991.

MARGOLIS, E.; JACQUES, F.O. \& SILVA, A.B. Determinação dos fatores da equação universal de perda de solo para as condições de Caruaru (PE). R. Bras. Ci. Solo, 9:165-169, 1985 .

MARQUES, J.J.G.S.M.; ALVARENGA, R.C. \& CURI, N. Erosividade das chuvas da região de Sete Lagoas, MG. Pesq. Agropec. Bras., 33:761-768, 1998.

MARQUES, J.Q.A.; BARRETO, G.B. \& BERTONI, J. Perdas por erosão no estado de São Paulo. Bragantia, 20:11431182, 1961. 
MARQUES, J.Q.A. \& BERTONI, J. Sistemas de preparo do solo com relação à produção e à erosão. Bragantia, 20:403459, 1961.

MARTINS-FILHO, E.C. \& SILVA, J.R.C. Comparação de métodos de avaliação da erodibilidade em Latossolo Vermelho-Amarelo distrófico. R. Bras. Ci. Solo, 9:175177, 1985.

MCDONALD, P., ed. The literature of soil science. Ithaca: Cornell University Press, 1994.

MELO-FILHO, J.F. \& SILVA, J.R.C. Erosão, teor de água no solo e produtividade do milho em plantio direto e preparo convencional de um Podzólico Vermelho-Amarelo do Ceará. R. Bras. Ci. Solo, 17:291-297, 1993.

MORAIS, L.F.B. \& COGO, N.P. Comprimentos críticos de rampa para diferentes maneos de resíduos culturais em sistema de semeadura direta em um Argissolo Vermelho da depressão central (RS). R. Bras. Ci. Solo, 25:1041-1051, 2001.

MOREIRA, M.C.; CECÍLIO, R.A.; PINTO, F.A.C. \& PRUSKI, F.F. Desenvolvimento e análise de uma rede neural artificial para estimativa da erosividade da chuva para o Estado de São Paulo. R. Bras. Ci. Solo, 30:1069-1076, 2006.

NASCIMENTO, P.C. \& LOMBARDI-NETO, F. Razão de perdas de solo sob cultivo de três leguminosas. Bras. Ci. Solo, 23:121-125, 1999.

NUNES-FILHO, J.; JACQUES, F.O.; MAFRA, R.C. \& SOUSA, A.R. Efeito do preparo do solo sobre as perdas por erosão e produção de milho num Podzólico Vermelho-Amarelo eutrófico de Serra Talhada (PE). R. Bras. Ci. Solo, 11:183$186,1987$.

NUNES-FILHO, J.; MAFRA, R.C.; SILVA, A.B. \& SOUSA, A.R. Práticas conservacionistas e as perdas por erosão na cultura do milho consorciado e isolado no sertão do Pajeú (PE). R. Bras. Ci. Solo, 14:62-72, 1990.

PRUSKI, F.F.; CECON, P.R.; FERREIRA, P.A. \& RAMOS, M.M. Model to design level terraces. J. Irrig. Drainage Eng., 123:8-12, 1997.

PRUSKI, F.F.; GRIEBELER, N.P. \& SILVA, D.D. Comparação entre dois métodos para determinação do volume de escoamento superficial. R. Bras. Ci. Solo, 25:403-410, 2001.

RACHWAL, M.F.G. \& DEDECEK, R.A. Influência da aeração e da disponibilidade hídrica em Cambissolos e Latossolos com diferentes níveis de erosão sobre a produtividade e a qualidade da cultura da batata. R. Bras. Ci. Solo, 20:485491, 1996.

RANIERI, S.B.L.; DOURADO-NETO, D.; SOUZA, M.P. \& SPAROVEK, G. Aplicação de índice comparativo no risco de degradação de terras. R. Bras. Ci. Solo, 22:751-760, 1998.

RANIERI, S.B.L.; FLANAGAN, D.C.; SPAROVEK, G. \& Jong van-LIER, Q. Erosion database interface (EDI): A computer program for georeferenced application of erosion prediction models. Computers Geosci., 28:661. 668, 2002.

REICHERT, J.M.; ELTZ, F.L.F.; NORTON, L.D. \& SCHAFER, M.J. Erosão em sulcos e entressulcos em razão do formato de parcela em Argissolo Vermelho-Amarelo arênico. Pesq. Agropec. Bras., 36:965-973, 2001.
ROQUE, C.G.; CARVALHO, M.P. \& PRADO, R.M. Fator erosividade da chuva de Pirajú (SP): Distribuição, probabilidade de ocorrência, período de retorno e correlação com o coeficiente de chuva. R. Bras. Ci. Solo, 25:147-156, 2001.

ROTH, C.H.; FARIAS, G.S. \& HENKLAIN, J.C. Avaliação do tamanho de gotas natural e simulada para o norte do Paraná. R. Bras. Ci. Solo, 9:171-174, 1985.

RUFINO, R.L. Avaliação do potencial erosivo da chuva para o estado do Paraná: Segunda aproximação. R. Bras. Ci. Solo, 10:279-281, 1986.

RUFINO, R.L.; BISCAIA, R.M. \& HENKLAIN, J.C. Influência das práticas de manejo e cobertura vegetal do cafeeiro nas perdas de solo. R. Bras. Ci. Solo, 9:277-280, 1985.

RUFINO, R.L.; BISCAIA, R.M. \& MERTEN, G.H. Determinação do potencial erosivo da chuva do estado do Paraná através da pluviometria: Terceira aproximação. R. Bras. Ci. Solo, 17:439-444, 1993.

SÁ, M.A.C.; CURI, N.;.LIMA, J.M.; MARQUES, J.J.G.S.M. \& MASSAROTO, J.A. Estimativa da erodibilidade pela desagregação por ultra-som e atributos de solos com horizonte B textural. Pesq. Agropec. Bras., 39:691-699, 2004 .

SALVIANO, A.A.C.; SPAROVEK, G. \& VIEIRA, S.R. Variabilidade espacial de atributos de solo e de Crotalaria juncea L. em área severamente erodida. R. Bras. Ci. Solo, 22:115-122, 1998

SCHAEFER, C.E.R.; ALBUQUERQUE, M.A.; ALBUQUERQUE-FILHO, M.R.; PAIVA, K.W.N.; PRUSKI, F.F. \& SILVA, D.D. Perdas de solo, nutriente, matéria orgânica e efeitos microestruturais em Argissolo Vermelho-Amarelo sob chuva simulada. Pesq. Agropec. Bras., 37:669-678, 2002.

SCHAFER, M.J.; CASSOL, E.A.; ELTZ, F.L.F.; REICHERT, J.M. \& REINERT, D.J. Erosão em sulcos em diferentes preparos e estados de consolidação do solo. R. Bras. Ci. Solo, 25:419-430, 2001a.

SCHAFER, M.J.; CASSOL, E.A.; REICHERT, J.M. \& REINERT, D.J. Erosão em entressulcos em diferentes preparos e estados de consolidação do solo. R. Bras. Ci. Solo, 25:431-441, 2001b.

SCHICK, J.; BALBINOT-JUNIOR, A.A.; BATISTELA, O. \& BERTOL, I. Erosão hídrica em Cambissolo húmico alumínico submetido a diferentes sistemas de preparo e cultivo do solo: Perdas de solo e água. R. Bras. Ci. Solo, 24:427-436, 2000

SILVA, A.B.; MARGOLIS, E.; RESENDE, M. \& SOUSA, A.R. Mobilização do solo, erosão e produtividade de milho e feijão em um regossolo no agreste pernambucano. Pesq. Agropec. Bras., 34:299-307, 1999.

SILVA, A.M. Rainfall erosivity map for Brazil. Catena, 57:251259, 2004

SILVA, I.F.; ANDRADE, A.P. \& CAMPOS-FILHO, O.R. Erodibilidade de seis solos do semi-árido paraibano obtida com chuva simulada e método nomográfico. R. Bras. Ci. Solo, 10:283-287, 1986. 
SILVA, I.F.; ANDRADE, A.P.; CAMPOS-FILHO, O.R. \& OLIVEIRA, F.A.P. Efeito de diferentes coberturas vegetais e práticas conservacionistas no controle da erosão. R. Bras. Ci. Solo, 10:289-292, 1986.

SILVA, M.L.N.; BLANCANEAUX, P.; CURI, N. \& FREITAS, P.I. Índice de erosividade das chuvas da região de Goiânia (GO). Pesq. Agropec. Bras., 32:977-985, 1997a.

SILVA, M.L.N.; BLANCANEAUX, P.; CURI, N. DE LIMA \& FREITAS, P.I. Relação entre parâmetros da chuva e perdas de solo e determinação da erosividade de um Latossolo Vermelho-Escuro em Goiânia (GO). R. Bras. Ci. Solo, 21:131-137, 1997b.

SILVA, J.R.C. \& DIAS, A.S. A erosividade das chuvas em Fortaleza (CE). II correlação com o coeficiente de chuva e atualização do fator R no período de 1962 a 2000. R. Bras. Ci. Solo, 27:347-354, 2003.

SILVA, J.R.C. \& PAIVA, J.B. Retenção de sedimentos por cordões de pedra em contorno em uma encosta de litossolo. R. Bras. Ci. Solo, 9:77-80, 1985.

SILVA, M.L.N.; CURI, N.; LIMA, J.M.; FERREIRA, D.F. \& FERREIRA, M.M. Proposição de modelos para estimativa da erodibilidade de Latossolos brasileiros. Pesq. Agropec. Bras., 34:2287-2298, 1999.

SILVA, M.L.N.; CURI, N.; LIMA, J.M. \& FERREIRA, M.M. Avaliação de métodos indiretos de determinação da erodibilidade de latossolos brasileiros. Pesq. Agropec. Bras., 35:1207-1220, 2000.

SILVA, M.L.N.; CURI, N.; FERREIRA, M.M.; LOMBARDINETO, F. \& OLIVEIRA, M.S. Comparação entre métodos direto e indireto para determinação da erodibilidade em Latossolos sob cerrado. Pesq. Agropec. Bras., 29:17511761,1994

SPAROVEK, G.; ALISON, J.; DE-MARIA, I.C.; GASSNER, A.; RANIERI, S.B.L.; SANTOS, R.F. \& SCHNUG, E. A conceptual framework for the definition of the optimal width of riparian forests. Agric. Ecosyst. Environ., 90:169175, 2001.

SPAROVEK, G.; ALOISI, R.R.; LIER, Q.J.V. \& VIDALTORRADO, P. Previsão do rendimento de uma cultura em solos de Piracicaba em função da erosão. R. Bras. Ci. Solo, 17:465-470, 1993.

SPAROVEK, G.; BACCHI, O.O.S.; DE-MARIA, I.C.; RANIERI, S.B.L. \& SCHNUG, E. Comparison of three water erosion prediction methods (137Cs, WEPP, USLE) in south-east brazilian sugarcane production. Tropenlandwirt, Witzenhausen 1, 101:107-118, 2000.

SPAROVEK, G. \& DE-MARIA, I.C. Multiperspective analysis of erosion tolerance. Sci. Agríc., 60:409-416, 2003.

SPAROVEK, G.; HORNINK, S. \& SCHNUG, E. A solution for worn-out tires, gully erosions, forests and dengue fever. Landbauforschung Volkenrode, 51:95-99, 2001.

SPAROVEK, G.; RANIERI, S.B.L.; SCHNUG, E.; SILVA, E.F \& WEILL, M.A.M. The life-time concept as a tool for erosion tolerance definition. Sci. Agríc., 54:130-135, 1997.
SPAROVEK, G.; ROCHELE, T.C.P.; SHAYER, E.P.M.; TERAMOTO, E.R. \& TORETA, D.M. Erosão simulada e a produtividade da cultura do milho. R. Bras. Ci. Solo, 15:363-368, 1991.

SPAROVEK, G. \& SCHNUG, E. Temporal erosion-induced soil degradation and yield loss. Soil Sci. Soc. Am. J., 65:1479-1486, 2001b.

SPAROVEK, G. \& SCHNUG, E. Soil tillage and precision agriculture. A theoretical case study for soil erosion control in Brazilian sugarcane production. Soil Tillage Res., 61:4754, 2001a.

STRECK, E.V. \& COGO, N.P. Reconsolidation of the soil surface after tillage descontinuity, with and without cultivation, related to erosion, and its prediction with RUSLE. R. Bras. Ci. Solo, 27:141-151, 2003.

TAVORA, M.R.P.; HERNANDEZ, F.F.F.; MOREIRA, E.G.S.; SAUNDERS, L.C.U. \& SILVA, J.R.C. Perdas de água, solo e nutrientes em Latossolo Vermelho-Amarelo distrófico em Ubajara (CE). R. Bras. Ci. Solo, 9:63-66, 1985a.

TAVORA, M.R.P.; MOREIRA, E.G.S. \& SILVA, J.R.C. Erodibilidade de dois solos da região de Ibiapaba, estado do Ceará. R. Bras. Ci. Solo, 9:59-62, 1985b.

TENBERG, A.; DECHEN, S.C.F. \& STOCKING, M.A. The impact os erosion on soil productivity - na experimental design applied in São Paulo state, Brazil. Geografiska Ann., 79:95-107, 1997.

van BAREN, J.H.V.; HARTEMINK, A.E. \& TINKER, P.B. 75 years the International Society of Soil Science. Geoderma, $96: 1-18,2000$

Jong van-Lier, Q.; BLOEM, E.M.; FLANAGAN, D.C.; SCHNUG, E. \& SPAROVEK, G. Runoff mapping using WEPP erosion model and GIS tools. Computers Geosci., 30:1270-1276, 2005.

VEIGA, M.; CABEDA, M.S.V. \& REICHERT, J.M. Erodibilidade em entressulcos de solos do Rio Grande do Sul. R. Bras. Ci. Solo, 17:121-128, 1993.

VERDADE, F.C.; GROHMANN, F. \& MARQUES, J.Q.A. Perdas de elementos nutritivos pela erosão. Nitrogênio e suas relações com as quantidades existentes no solo e na água da chuva. Bragantia, 15:99-106, 1956.

VIEIRA, M.J.; CASSOL, E.A. \& COGO, N.P. Perdas por erosão em diferentes sistemas de preparo do solo para a cultura da soja em condições de chuva simulada. R. Bras. Ci. Solo, 2:209-214, 1978.

VIEIRA, S.R. \& LOMBARDI-NETO, F. Variabilidade espacial do potencial de erosão da chuva do estado de São Paulo. Bragantia, 54:405-412, 1995.

VOLK, L.B.S.; COGO, N.P. \& STRECK, E.V. Erosão hídrica influenciada por condições físicas de superfície e subsuperfície do solo resultantes do seu manejo, na ausência de cobertura vegetal. R. Bras. Ci. Solo, 28:763774,2004 